one centre the committee system is brought to bear on the most trivial details of domestic management; in another case a central authority practically decides even such matters as forfeiture of scholarships in cases of discipline. It may be that these divergences are the result of varying local conditions, but a study of them might well be extended to our universities.

Since the preceding notice was written, we have received a criticism of Mr. Cooke's report by President R. C. Maclaurin, of the Massachussets Institute of Technology, published in Science, xxxiii., 838, pp. IOI-IO3 (January 20). Attention is particularly directed to the fact that most of the points raised in the report are not new. "It is full of commonplaces, and there is scarcely a question raised that has not been discussed ad nauseam by college professors and other officers. It is not lacking in confidence. One marvels at the temerity even of an 'efficiency engineer' who can lay down the law so definitely as to how to teach physics, how to conduct a recitation, how to carry on research, when most of us who have devoted our whole lives to such problems are far less confident." President Maclaurin specially condemns the "studenthour" standard of efficiency and the proposal for inspection of research, the futility of which has been pointed out above, and he instances his point by the following imaginary dialogue between Newton and the "superintendent of buildings and grounds, or other competent authority."

"Superintendent: Your theory of gravitation is hanging fire unduly. The director insists on a finished report, filed in his office, by $9 \mathrm{a} . \mathrm{m}$. Monday next, typewritten, and the main points underlined. Also a careful estimate of the cost of the research per studenthour.

"Nervton: But there is one difficulty that has been puzzling me for fourteen years, and I am not quite . .

"Superintendent (with snap and vigour): Guess you had better overcome that difficulty by Monday morning or quit."

G. H. BRYAN.

\section{THE MOTIONS OF THE PLANETS JUPITER AND SATURN.}

THE January number of the South African Journal of Science contains. an excellent paper by $\mathrm{Mr}$. R. T. A. Innes on Le Verrier's theory of the motion of the planets Jupiter and Saturn. The title scarcely covers all that is in the paper, for the author concludes with numerical calculations, based upon formulæ developed by himself in the Monthly Notices for I909, which must constitute a considerable step towards a revision of Le Verrier's theory.

Mr. Innes's chief criticism on Le Verrier is that he has taken $9^{\circ} 7367408$ instead of $9^{\circ} 73655^{14}$ for the log ratio of the mean distances of Jupiter and Saturn, an error approximately of one part in two thousand.

The error is, however, considerably magnified when its effects upon the series representing the reciprocal of the distance between Jupiter and Saturn are considered, and the author's final conclusion is that the fourth significant figure always, and the third often, is incorrect in Le Verrier's perturbations. The error arose because Le Verrier used the mean distances corresponding in elliptic theory with the mean motions and neglected the systematic effects of the perturbations. Jupiter, for instance, on a distant planet like Neptune, may be approximately considered as coalescing with the sun, making that body heavier by one-thousandth part, and consequently the mean distance of Neptune greater by one part in three thousand.

No. $2 \mathrm{I} 6 \mathrm{I}$, VOL. 86]
The mean distance of Saturn needs correction by a greater fraction, nearly one part in two thousand; for when Jupiter is between Saturn and the sun, its attraction amounts to about four parts in a thousand of that of the sun, and the average is thus. raised.

Le Verrier's omission is unimportant in all other cases. For the four inner planets the perturbations are so small that the third significant figure is insensible, and for Neptune and Uranus the increment due to Jupiter is practically the same and the ratio inappreciably altered.

We quote, for ready reference, a most valuable table :-

\begin{tabular}{|c|c|c|c|c|}
\hline \multicolumn{2}{|l|}{ Planet } & \multicolumn{3}{|c|}{ Log mean distance } \\
\hline & & Elliptic theory & & Actual \\
\hline Mercury & & & & 9.587 \\
\hline & $\cdots$ & 337 & $\ldots$ & 985933745 \\
\hline & $\ldots$ & 0000 0001 & $\ldots$ & 0.0000 \\
\hline M & $\ldots$ & 182897 & $\ldots$ & 0.182896 \\
\hline Jupiter & $\ldots$ & 0.71623747 & $\ldots$ & 0.71623339 \\
\hline & $\cdots$ & 0.97949655 & $\ldots$ & 0.97967915 \\
\hline$U_{r}$ & $\cdots$ & 1.282900 & $\cdots$ & I 283097 \\
\hline eptune & $\ldots$ & $\mathrm{I} 44779466 \mathrm{I}$ & $\ldots$ & 1478143 \\
\hline
\end{tabular}

Some obiter dicta in the paper are of great interest. Here is one :-

"So far as merely obtaining an ephemeris goes, it is probable that the method of special perturbations would have given one for 300 years or so with less labour than was involved in either the theories of Hill or Le Verrier."

This sets one thinking why we want the theories. Of course, we want the general results of theory, the first and foremost being that the mean distances are subject to no secular changes. And we want the outline of . the theory of long-period inequalities with rough estimates of the numerical coefficients. But an ephemeris of Neptune could be obtained by special perturbations at $5^{12}$-day intervals (using a power of $2)$; fifty intervals of 5 I2 days each would cover the period from its discovery to the present day-a month's work.

It is beginning to be recognised that the "theory, good for ages, in which $t$ alone has to be substituted," is incomplete. Le Verrier gave some results for the earth 100,000 years ago, based on his theory. If similar theories existed for the minor planets; we doubt, if we should see Eros falling within the orbit of Mars, the Trojan group being captured by Jupiter, and the zone corresponding to a mean motion double that of Jupiter being cleared of small planets. Possibly these phenomena are due to the secular effects of small causes not at present taken into account. We want, therefore, in the cheapest possible way, to multiply accurate ephemerides for comparison with observation.

\section{THE ANTON DOHRN MEMORIAL FUND.}

THE zoological station at Naples occupies a unique position among the biological institutions of the world. It is not only the oldest, the largest, and the best equipped of the biological stations, but it: has maintained throughout its existence its thoroughly international character. The founder of this important institution, Dr. Anton Dohrn, died on September 26, I909, and at the eighth International Zoological Congress, held at Graz during August, I9Io, it was decided to raise a fund for an international memorial to commemorate his great achievement.

In case some doubt may be entertained as to the maintenance of the international character of the institution which is now under the management of Prof. Reinhard Dohrn, one of the sons of the distinguished founder, it may be remarked that Prof. von 
Graff, the president of the congress, has ascertained that no guarantee has been given for the maintenance of the station by any Government or academy, and that, by the terms of an agreement with the city of Naples, no special rights can be obtained in it by any such body during the period of agreement. Prof. Reinhard Dohrn has assumed the entire responsibility of continuing the work of the station, with the provision that, in the event of his death, the responsibility shall pass to another member of the Dohrn family, and subject to the understanding that the station shall remain a completely international institution, in the benefits of which all countries have the right of participating.

The memorial is to take the form of a portrait in bas-relief, to be placed in the zoological station, and of a fund for promoting the efficiency of the station as an international institution for carrying on research in biology.

The amount collected will be reported in ${ }^{1} 9^{1} 3$ to the ninth International Congress, which will be asked to formulate the conditions under which the fund shall be handed over to the zoological station. The biologists resident in this country who had signified their sympathy with the proposal to establish the memorial fund, and whose names appear in the international list submitted to the Graz meeting, were invited to attend a meeting which was held in the Natural History Museum, Cromwell Road, S.W., on February 3. As a result of this meeting a number of zoologists, representing the principal centres of research in the British Islands, have been asked to form a sub-committee for the British Empire, in order to assist in the work of the international committee, and of this subcommittee Dr. Sidney F. Harmer, F.R.S., was appointed chairman.

Contributions varying in amount from $5 l .5 s$. to Ios. $6 d$. have already been paid or promised, and it is hoped that the result of the appeal for subscriptions which is being issued will show that Anton Dohrn's great achievement, the establishment and management of the Stazione Zoologica at Naples, is as fully appreciated here as it is in other parts of the world.

Additional subscriptions may be paid to Prof. S. J. Hickson, F.R.S., of the University of Manchester, who is acting as secretary and treasurer of the British subcommittee. Prof. Hickson will be glad to send a copy of the circular which has been issued to any subscriber whose name has been accidentally omitted in drawing up the list of addresses.

\section{NOTES.}

WE are asked to state that the annual meeting of the British Science Guild, to be held on Friday, April 7, at the Mansion House, will be opened at 5.0 p.m. instead of 4.0 p.m., as previously announced. The speakers will be:-The Lord Mayor, Viscount Haldane, Sir William White, K.C.B., F.R.S., Sir Albert Spicer, Prof. J. Perry, F.R.S., Dr. R. T. Glazebrook, C.B., F.R.S., Prof. A. D. Waller, F.R.S., and Sir Philip Magnus, M.P.

THE Bakerian lecture of the Royal Society will be delivered by the Hon. R. J. Strutt, F.R.S., on Thursday next, April 6, on the subject of "A Chemically Active Modification of Nitrogen produced by the Electric Discharge." The lecture will be illustrated by experiments.

At the anniversary meeting of the Royal Irish Academy on March 16 the following were elected honorary members in the section of science:-Hendrik Antoon Lorentz, Berlin; Max Planck, Berlin; Right Hon. Sir Henry Enfield Roscoe, London; and Charles Sprague Sargent, Cambridge, Mass., U.S.A.

$$
\text { NO. } 216 \mathrm{I} \text {, VOL. 86] }
$$

ThE proposal to establish a museum for London comes at a moment when the subject is better understood than at any other time. Museum work has taken its place in educational requirements, and local history has been shown to be of supreme importance in the development of good citizenship. Of all localities, London is the outstanding city in Britain possessing a history of unique importance. The site of London has been occupied by man since Palæolithic times, through Neolithic times to the historic period when, as a Celtic stronghold, it first became the settlement of a community. As a Roman city, it possesses the finest remains of Roman antiquities in all Britain. AngloSaxon, Danish, and later periods are represented by fine series of objects. Remains of beautiful Tudor architecture have been excavated and preserved by the London County Council, which has also preserved and stored every object of interest discovered during its numerous works; the City Corporation has assiduously collected for many years objects discovered in the city, and there are many local collections of considerable interest, both public and private. All this means that there exists already the materials for a London museum from prehistoric to modern times, and it is matter for intense gratification that $\mathrm{Mr}$. Harcourt, when First Commissioner of Works, should have set his hand to this great project and should have carried it through with the aid of a munificent private benefactor. That London should have its own museum of material history as well as its published records is all to the good, though it is late in the day. It is fortunate that the delay in the accomplishment is accompanied by a goodly storehouse of objects awaiting exhibition in a properly organised museum.

Lord Curzon of Kedleston has consented to allow himself to be nominated by the council of the Royal Geographical Society as president of the society in succession to Major Leonard Darwin, who will retire at the anniversary meeting on May 22, after occupying the presidential chair for three years. The annual dinner of the society will be held this year in the Great Hall of the Hotel Cecil on May 26.

A Reuter message from Paris on March 25 states that M. Sommer, the aviator, has made a flight at Mouzon in a biplane with twelve passengers on board, the total weight being $1439 \mathrm{lb}$.

By direction of the London County Council, a tablet has been affixed to No. 32 Soho Square (the National Hospital for Diseases of the Heart), where for many years lived Sir Joseph Banks, who for forty-one years-from ${ }_{1778}$ to 1820-was president of the Royal Society.

THE meetings of the Institution of Naval Architects will be held at the Royal Society of Arts on April 5-7. In consequence of the death of the late president of the institution, Earl Cawdor, the annual dinner will not be held this year. On April 5 the presentation of the institution premium to Mr. T. B. Abell will be made.

A BRASS tablet to the memory of the late Mr. Cox has been placed in the Hackney Town Hall. The tablet, which was provided by residents in Hackney, bears the words :"In honour of Harry William Charles Cox, consulting electrician, who died at Hackney July 9, 1910. He contracted a malignant disease while perfecting apparatus for adapting the X-rays to the relief of human suffering."

THE Bessemer gold medal of the Iron and Steel Institute will this year be awarded to Prof. Henri Le Chatelier, the eminent French metallurgist, in recognition of his 